\title{
The Attitude and Behavior of Chinese Residents During the Outbreak of Coronavirus Disease 2019: A Cross-Sectional Study
}

\author{
Yanfei $\mathrm{Li}^{1}$, Siyun Wang ${ }^{2}$, Cuiqing Liu ${ }^{3}$, Weiju Chen ${ }^{4,}$ * \\ ${ }^{1}$ Department of Spinal and Trauma, The First Affiliated Hospital of Jinan University, Guangzhou, China \\ ${ }^{2}$ Nursing School, Sichuan College of Traditional Chinese Medicine, Mianyang, China \\ ${ }^{3}$ Department of Nursing, The First Affiliated Hospital of Jinan University, Guangzhou, China \\ ${ }^{4}$ School of Nursing, Jinan University, Guangzhou, China
}

Email address:

chenweiju@126.com (Weiju Chen)

${ }^{*}$ Corresponding author

\section{To cite this article:}

Yanfei Li, Siyun Wang, Cuiqing Liu, Weiju Chen. The Attitude and Behavior of Chinese Residents During the Outbreak of Coronavirus Disease 2019: A Cross-Sectional Study. American Journal of Nursing Science. Vol. 10, No. 3, 2021, pp. 142-150. doi: 10.11648/j.ajns.20211003.11

Received: March 7, 2021; Accepted: April 2, 2021; Published: April 29, 2021

\begin{abstract}
Objective: The objective of this study was to assess the behavior and attitude of Chinese residents about the prevention of COVID-19 during the outbreak of global infectious diseases. Design and Methods: A cross-sectional online survey of Chinese residents was conducted using convenience and snowball sampling techniques. Online questionnaire survey was conducted from March 7 to March 14, 2020, and the respondents were community residents who could operate smart phones independently. By 24:00 on March 14, 908 questionnaires had been collected, of which 899 were valid. Findings: Focus on the availability and effectiveness of older adults in accessing vectors for epidemic information. Pay attention to the attitude and behavior of disease prevention measures of the group with low educational background. Monthly income is an important factor in adopting healthy behaviors. Therefore, in the case of shortage of epidemic prevention manpower resources, the focus will be more epidemic prevention manpower distribution in low-income, low educational population population. The community residents with high education and high income can serve as the secondary key area. Give play to the social function of all walks of life to ensure the supply of life materials. In the case of shortage of materials, priority should be given to the distribution of materials to prevent the epidemic, to ensure the basic operation of the city. Positive self-efficacy can encourage people to adhere to healthy behaviors, so as to ensure their health without being infected. Conclusions: In terms of the implementation of epidemic prevention measures, the government or social organizations should pay more attention to the characteristics of the key population and carry out targeted measures, especially the elderly, the elderly living alone, the low-income people with low educational background. At the same time, we will focus on the compliance of prevention and control measures for low-income and low-educated people, and intensify publicity and material support. The government should give full play to the social function of all walks of life, ensure the supply of materials for people who are quarantined at home, intensify the media propaganda, and release the epidemic information in an open, transparent, accurate and timely manner, so as to increase the information of residents against the virus.
\end{abstract}

Keywords: Coronavirus Disease 2019 (COVID-19), Health Belief Model, Chinese Residents, A Cross-Sectional Study

\section{Introduction}

In 2020, global covid-19 outbreak occurred, and covid-19 has become a global epidemic disease. On January 12, 2020, the world health organization (WHO) officially named the novel coronavirus causing pneumonia 2019-ncov (2019 novel coronavirus) [1]. Novel coronavirus is a type $\beta$ coronavirus, which is highly infectious and susceptible. Respiratory droplets and close contact are the main means of transmission [2], Aerosol transmission, fecal mouth transmission, conjunctival transmission, mother-to-child vertical 
transmission and other forms still need to be further confirmed [3]. People infected with a novel coronavirus have been clearly identified as the main source of infection, with the rapid spread of the disease, Studies have shown that the coronavirus may have been transmitted by the asymptomatic carrier [4]. Some of the first detailed estimates of these covert cases suggest that they could represent some $60 \%$ of all infections [5]. Since the latent infection always does not appear clinical symptoms, it is often unable to timely and effectively identify, easy to form loopholes in prevention and control measures, difficult to be timely diagnosed and isolated, easy to cause the accumulation of infection sources in the community, resulting in increased difficulty in controlling the spread of the disease. 2019-nCoV has also been shown to be more infectious than SARS-CoV and MERS-CoV [6].

Based on the evidence of a rapidly increasing incidence of infections [7] and the possibility of transmission by asymptomatic carriers [8], 2019-nCoV can be transmitted effectively among humans and exhibits high potential for a pandemic [9]. The pandemic is accelerating. It took 67 days from the first reported case to reach the first 100,000 cases, 11 days for the second 100,000 cases and just 4 days for the third 100,000 cases [10]. With the spread of the epidemic, the number of overseas patients is on the rise, especially in the United States, Italy, Spain, Germany and other countries are the most serious. The World Health Organization (WHO) on March 11, 2020, has declared the novel coronavirus (COVID-19) outbreak a global pandemic. As of 0:00 Beijing time on March 31, the number of confirmed cases worldwide reached 697,244. 203 countries have now been Confirmed, and more than 9,000 people have lost their lives. There is currently no vaccine to prevent coronavirus disease 2019 (COVID-19). The best way to prevent illness is to avoid being exposed to this virus. In response to pandemic trends, the world health organization recommended basic protective measures against the new coronavirus. (1) Regularly and thoroughly clean your hands with an alcohol-based hand rub or wash them with soap and water. (2) Maintain at least 1 meter (3 feet) distance between yourself and anyone who is coughing or sneezing. (3) Avoid touching eyes, nose and mouth. Because that hands touch many surfaces and can pick up viruses. (4) Practice respiratory hygiene. (5) If you have fever, cough and difficulty breathing, seek medical care early [11].

The downward trend in China's overall epidemic curve suggests that limiting the movement of people, reducing exposure, and frequent multi-channel dissemination of critical prevention information (for example, hand washing, mask wearing and medical information), as well as mobilizing a multisectoral rapid response, can help contain the outbreak [12]. The director-general of the world health organization also pointed out that China's epidemic prevention experience is worth learning from the world [13]. In the early stage of the epidemic, in order to further control the development of the epidemic, China launched a first-level response to public health emergencies, and the country entered a first-level combat readiness. The government took compulsory measures in accordance with the law to stop large-scale mass activities.
All places not necessary for daily life of residents shall be closed for business. All training institutions in the city will stop online activities and provide offline services. Suspension of work, suspension of business, suspension of school, residents in public places must wear masks. We will strictly carry out health and quarantine inspection, set up temporary transportation and health quarantine stations, and implement compulsory health and quarantine measures. The floating population shall be subject to preventive work, control measures shall be implemented, patients and suspected patients with infectious diseases shall be isolated, observed and treated on the spot, and close contacts shall be subject to intensive or home-based medical observation according to the circumstances. To carry out the outbreak clues investigation and virus detection, the disease control agency to Hubei area to even fever cases to carry out a novel coronavirus nucleic acid detection and epidemiological clues investigation. We focused on coordinating quality medical resources to cure pneumonia cases infected by novel coronavirus and strengthened the management of nosocomial infection in medical institutions. To carry out mass prevention and treatment activities, the streets, townships (towns), neighborhood committees and village committees shall assist the administrative departments of public health and other relevant units and medical institutions in the collection and reporting of epidemic information, the isolation of scattered personnel and the implementation of public health measures 。 Relevant departments focus on maintaining social stability, ensuring the supply of commodities and curbing price inflation。Information release timely and actively, accurately grasp, seek truth from facts, correctly guide public opinion, pay attention to social effect. By the end of January 2020, all provinces in China will implement the state-initiated first-level response measures, and the whole people will participate in overcoming the difficulties. In China, where the epidemic is gradually getting better, the ability of residents to stick to a certain behavior also depends on their attitude towards the behavior.

The Health Belief Model (HBM) is a psychosocial model that accounts for health behaviors by identifying factors associated with individuals' beliefs which influence their behaviors [14]. Health belief model (HBM) is a theoretical model that explains health-related behaviors using social psychological methods. This model was assumed that: value avoiding illnesses/getting well and expect that a specific health action may prevent illness. The expectancy was further delineated in terms of the individual's estimates of personal susceptibility to and perceived severity of all illness, and of the likelihood of being able to reduce that threat through personal action. The health belief model is widely used to explain people's preventive health care behavior and analyze the influencing factors of behavioral compliance. Based on the health belief theory, this paper designed a survey of Chinese residents' attitudes and behaviors towards diseases in the COVID 19 period in terms of health perception, perceived behavioral benefits, perceived behavioral disorders, self-efficacy and prompting factors, I hope to learn about the 
attitude and actions of Chinese citizens in fighting against the epidemic among the whole population, so as to serve as a reference for other countries to prevent and control the epidemic.

\section{Methods}

\subsection{Objective}

The objective of this study was to assess the behavior and attitude of Chinese residents about the prevention of COVID-19 during the outbreak of global infectious diseases.

\subsection{Design and Methods}

A cross-sectional online survey of Chinese residents was conducted using convenience and snowball sampling techniques. Online questionnaire survey was conducted from March 7 to March 14, 2020, and the respondents were community residents who could operate smart phones independently. By 24:00 on March 14, 908 questionnaires had been collected, of which 899 were valid, with an effective rate of $99 \%$. The self-designed questionnaire (Table 1.) was distributed through the network, and the questionnaire was in the form of anonymity. The questionnaire included general demographic characteristics and 33 items designed on the theoretical basis of the health belief model, The 33 items were composed of 10 items of perceived threat (perceived susceptibility $3 \mathrm{~A}$, perceived severity $7 \mathrm{~B}$ ), 7 items of perceived benefits, 7 items of perceived barriers, 5 items of self-efficacy, and 4 items of cues to action. The items had a 5-point response scale: 5=Strongly impossible (Not serious at all $\backslash$ Not difficult at all $\backslash$ Not high at all $\backslash$ Totally useless $\backslash$ Not sufficient), 4=Impossible (Not serious $\backslash$ Not difficult $\backslash$ Not high $\backslash$ useless $\backslash$ Insufficient), 3=General, 2= Possible (serious $\backslash$ difficult $\backslash$ high $\backslash$ useful \ sufficient), and 1=Strongly possible (Strongly serious $\backslash$ Strongly difficult $\backslash$ Very high $\backslash$ Very useful $\backslash$ Very sufficient). The content validity of this questionnaire is 0.925 .

Table 1. Variable of Health belief model.

\begin{tabular}{|c|c|c|}
\hline Constructs of HBM & Variable & Terms \\
\hline & A1 & Do you think you may be infected with COVID-19? \\
\hline $\begin{array}{l}\text { Perceived } \\
\text { susceptibility }\end{array}$ & A2 & $\begin{array}{l}\text { Do you think there may be patients diagnosed with COVID-19 around your place of residence in recent? (Such as } \\
\text { neighbors, same district, same street) }\end{array}$ \\
\hline \multirow{7}{*}{$\begin{array}{l}\text { Perceived } \\
\text { severity }\end{array}$} & A3 & Do you think it is possible for you to contact with people who have been infected with COVID-19 when you go out? \\
\hline & B1 & Do you think epidemic situation is serious of COVID-19 in China? \\
\hline & B2 & Do you think the COVID-19 epidemic is serious in your area? \\
\hline & B3 & Do you think the condition will be serious if you are infected with COVID-19? \\
\hline & B5 & If you get COVID-19, What do you think how likely is it to cure? \\
\hline & B6 & If you get COVID-19 disease and cured, What do you think how likely is it to have severe sequel in the future? \\
\hline & B7 & If you get COVID-19, What do you think how likely is it to die? \\
\hline \multirow{5}{*}{$\begin{array}{l}\text { Perceived } \\
\text { benefits }\end{array}$} & $\mathrm{C} 1$ & Do you think wearing a mask may prevent COVID-19? \\
\hline & $\mathrm{C} 2$ & $\begin{array}{l}\text { Do you think it is possible to avoid being infected by the COVID-19 if you live at home without going to a crowded } \\
\text { public place? }\end{array}$ \\
\hline & $\mathrm{C} 3$ & Do you think it is possible to washing your hands frequently to prevent COVID-19? \\
\hline & C6 & Do you think it is possible to regular rest and drinking water to prevent COVID-19? \\
\hline & $\mathrm{C} 7$ & Do you think it is possible to prevent COVID-19 by scrubbing / spraying clothing and mask with disinfectant? \\
\hline \multirow{7}{*}{ Perceived barriers } & D1 & Do you think it is difficult to buy a mask? \\
\hline & D2 & Do you think it is difficult to wear a mask to go to public places? \\
\hline & D3 & Do you think it is difficult to reduce go to public places? \\
\hline & D4 & Do you think it is difficult to buy Hand Sanitizer for hand washing? \\
\hline & D5 & Do you think it is difficult to washing hands you go home every time? \\
\hline & D6 & Do you think it is possibility that economic pressure makes you cannot isolated at home? \\
\hline & D7 & Do you think it is possibility that inadequate daily necessities will make you impossible to isolated at home? \\
\hline \multirow{5}{*}{ Self-efficacy } & E1 & Do you think your have adequate immunity system to prevent the COVID-19? \\
\hline & E2 & Do you think you can insist on wearing a mask until end of the epidemic? \\
\hline & E3 & Do you think you can insist on washing your hands you go home every time? \\
\hline & E4 & Is it possible that you will comply with the official requirements for epidemic prevention and control? \\
\hline & E5 & Is it possible that your family and friends will isolate at home initiatively? \\
\hline \multirow{2}{*}{ Cues to action } & F3 & Do you think that you have sufficient information to prevent and control the epidemic? \\
\hline & F4 & Do you think you can get information about COVID-19 epidemic prevention and control timely? \\
\hline
\end{tabular}

\subsection{Analytic Strategy}

Quantitative data were entered into Excel 2007 and SPSS 22.0 software for analysis, and the frequencies were used to describe the demographic characteristics. Independent-Samples Test were performed to evaluate the Behavior attitude classification and Sociological characteristics (gender and working condition), one way 
ANOVA of sample were performed to evaluate the behavior attitude classification and sociological characteristics (education $\backslash$ profession and income)

Spearman correlation coefficient of sample were performed to evaluate sociological characteristics and each behavior attitude.

\section{Result}

\subsection{Basic Information}

Demographic information is presented in Table 2. Of the
908 participants, 899 (99\%) completed and submitted correct information. The majority of participants were women $(698$ people, $77.6 \%$ ), the education level is mainly university (521 people), The number of medical workers was 320 , accounting for 35.6 percent of the total; During the epidemic prevention and control, 467 people lived at home to rest or work, accounting for $51.9 \%$ of the total. The vast majority of Chinese residents earn between $3000 \sim 6000$ yuan (almost 428 856 dollars) and between $6000 \sim 12000$ yuan (almost 856 1712 dollars).

Table 2. Demographic characteristics of the samples $(N=899)$.

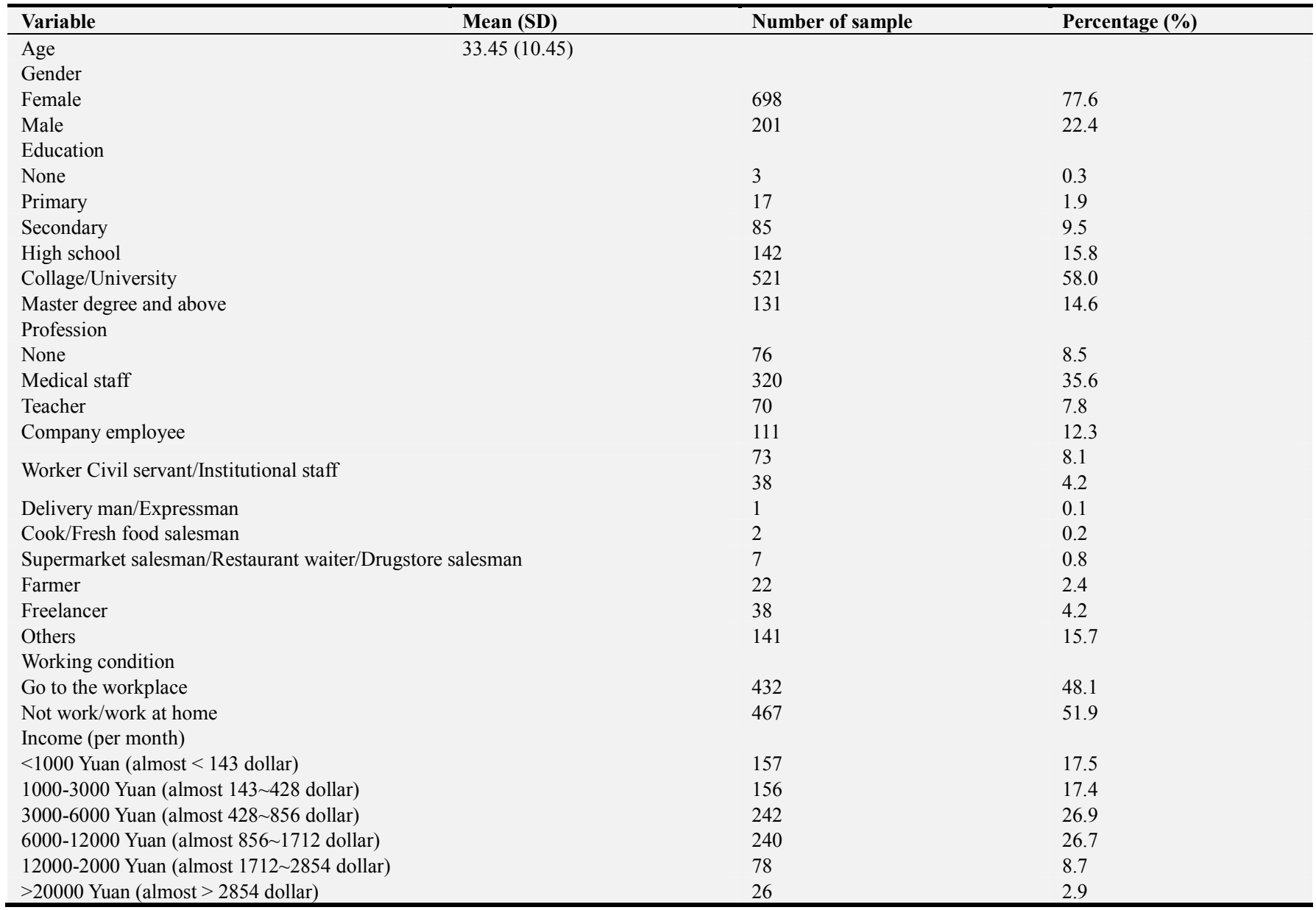

\subsection{Behavior Attitude Score Distribution}

The results of the residents' different performance in 5 aspects such as Perceived threat, Perceived benefits, Perceived barriers, Self-efficacy, Cues to action are shown in Table 3. In terms of Perceived threat, $34.5 \%$ of the residents believed that they could not be infected with covid-19, but $40.5 \%$ believed that they might be exposed to people from the novel coronavirus epidemic area. The vast majority of residents (51.7 percent) believe the country's outbreak is serious. The majority of the population $(44.6 \%)$ indicated that the epidemic severity in the region was moderate. $39.8 \%$ of the residents believe that COVID-19 is serious if infected. The vast majority of Chinese residents $(76.1 \%)$ have great confidence in the possibility of curing of COVID - 19 infection. $40 \%$ of the residents believe that COVID-19 will leave a serious sequelae after treatment.

In terms of Perceived benefits, $43.8 \%$ of residents believe it is possible to prevent viruses by wearing masks. $48.3 \%$ of the residents believed that it was possible to prevent COVID 19 infection by isolating it at home rather than in a crowded public place. $47.8 \%$ of residents believe frequent hand washing is very likely to prevent the virus. Novel coronavirus may also be prevented by window ventilation $(46.4 \%)$, oral administration of immune-enhancing drugs (39.8\%), regular rest, plenty of water (49.1\%), and disinfectant 
scrubbing/spraying of clothing or articles (55.6\%).

In terms of Perceived barriers, due to the lack of medical materials in the early stage of the epidemic, the majority of residents $(39.8 \%)$ think it is difficult to buy masks, and most of them think it is not difficult to wear masks in public places $(44.9 \%)$ or to reduce the number of times to public places $(51.2 \%)$ 。 Most residents think it is not difficult to buy hand sanitizer $(44.3 \%)$ or wash their hands every time when they go home $(45.6 \%)$. Some residents believe that economic pressure (32.4\%) and inadequacy of daily necessities (31.9\%) are the general conditions that lead to the possibility that they cannot be isolated at home.

In the aspect of Self - efficacy, The vast majority of residents $(48.4 \%)$ believe that their current state of health is resistant to the virus, that they are very likely to persist to the end of the epidemic by wearing a mask (61.1\%), and that they are very likely to persist in washing their hands after going home outdoors $(65.5 \%), 55.1 \%$ of the residents are very likely to do according to the epidemic prevention and control requirements issued by the country, and have strong confidence in the home quarantine of others (44.2\%).

In the aspect of Cues to action, The vast majority of residents $(49.8 \%)$ considered the precautions against novel coronavirus published in the news media or online official media to be very useful, They also believed that they had access to adequate information on the prevention and control of the epidemic (45.9\%) and could obtain timely information on the prevention and control of the epidemic (46.9\%).

Table 3. Behavior attitude score of the sample $N=899(\%)$.

\begin{tabular}{|c|c|c|c|c|c|}
\hline Terms & Strongly possible & Possible & General & Impossible & Strongly impossible \\
\hline A1 & $18(2.0)$ & $165(18.4)$ & $227(25.3)$ & $310(34.5)$ & $179(19.9)$ \\
\hline $\mathrm{A} 2$ & $32(3.6)$ & $246(27.4)$ & $253(28.1)$ & $263(29.3)$ & $105(11.7)$ \\
\hline A3 & $39(4.3)$ & $364(40.5)$ & $228(25.4)$ & $195(21.7)$ & $73(8.1)$ \\
\hline B4 & $51(5.7)$ & $257(28.6)$ & $397(44.2)$ & $143(15.9)$ & $51(5.7)$ \\
\hline B5 & $329(36.6)$ & $355(39.5)$ & $178(19.8)$ & $28(3.1)$ & $9(1.0)$ \\
\hline B6 & $109(12.1)$ & $360(40.0)$ & $310(34.5)$ & $94(10.5)$ & $26(2.9)$ \\
\hline $\mathrm{C} 1$ & $362(10.3)$ & $394(43.8)$ & $121(13.1)$ & $16(1.8)$ & $6(0.7)$ \\
\hline $\mathrm{C} 2$ & $434(48.3)$ & $274(30.5)$ & $97(10.8)$ & $68(7.6)$ & $26(2.9)$ \\
\hline $\mathrm{C} 3$ & $430(47.8)$ & $382(42.5)$ & $66(7.3)$ & $14(1.6)$ & $7(0.8)$ \\
\hline $\mathrm{C} 4$ & $350(38.9)$ & $417(46.4)$ & $100(11.1)$ & $23(2.6)$ & $9(1.0)$ \\
\hline C5 & $86(9.6)$ & $358(39.8)$ & $333(37.0)$ & $99(11.0)$ & $23(2.6)$ \\
\hline C6 & $226(25.1)$ & $441(49.1)$ & $182(20.2)$ & $41(4.6)$ & $9(1.0)$ \\
\hline $\mathrm{C} 7$ & $194(21.6)$ & $500(55.6)$ & $171(19.0)$ & $29(3.2)$ & $5(0.6)$ \\
\hline E2 & $549(61.1)$ & $263(29.3)$ & $62(6.9)$ & $19(2.1)$ & $6(0.7)$ \\
\hline E3 & $589(65.5)$ & $242(26.9)$ & $59(6.6)$ & $8(0.9)$ & $1(0.1)$ \\
\hline E4 & $495(55.1)$ & $315(35.0)$ & $79(8.8)$ & $8(0.9)$ & $2(0.2)$ \\
\hline E5 & $397(44.2)$ & $372(41.4)$ & $103(11.5)$ & $22(2.4)$ & $5(0.6)$ \\
\hline D6 & $101(11.2)$ & $255(28.4)$ & $291(32.4)$ & $163(18.1)$ & $89(9.9)$ \\
\hline D7 & $122(13.6)$ & $283(31.5)$ & 287 (31.9) & $143(15.9)$ & $64(7.1)$ \\
\hline Terms & Strongly serious & Serious & General & Not serious & Not serious at all \\
\hline B1 & $247(27.5)$ & $465(51.7)$ & $143(15.9)$ & $38(4.2)$ & $6(0.7)$ \\
\hline B2 & $21(2.3)$ & $143(15.9)$ & $401(44.6)$ & $265(29.5)$ & $69(7.7)$ \\
\hline B3 & $133(14.8)$ & $358(39.8)$ & $318(35.4)$ & $69(7.7)$ & $21(2.3)$ \\
\hline Terms & Strongly difficult & Difficult & General & Not difficult & Not difficult at all \\
\hline D1 & $265(29.5)$ & $358(39.8)$ & $200(22.2)$ & $63(7.0)$ & $13(1.4)$ \\
\hline D2 & $12(1.3)$ & $54(6.0)$ & $144(16.0)$ & $404(44.9)$ & $285(21.7)$ \\
\hline D5 & $6(0.7)$ & $17(1.9)$ & $76(8.5)$ & $410(45.6)$ & $390(43.4)$ \\
\hline Terms & Very high & High & General & Not high & Not high at all \\
\hline $\mathrm{F} 1$ & $279(31.0)$ & $105(11.7)$ & $181(20.1)$ & $309(34.4)$ & $25(2.8)$ \\
\hline Terms & Very useful & Useful & General & Useless & Totally useless \\
\hline $\mathrm{F} 2$ & $448(49.8)$ & $392(43.6)$ & $59(6.6)$ & 0 & 0 \\
\hline Terms & Very sufficient & Sufficient & General & Insufficient & Not sufficient at all \\
\hline F3 & $342(38.0)$ & $413(45.9)$ & $140(15.6)$ & $2(0.2)$ & $2(0.2)$ \\
\hline Terms & Very timely & Timely & General & Not timely & Not timely at all \\
\hline F4 & $351(39.0)$ & $422(46.9)$ & $117(13.0)$ & $7(0.8)$ & $2(0.2)$ \\
\hline
\end{tabular}

\subsection{The Correlation Between Sociological Characteristics and Behavioral Attitudes}

There was a spearman correlation coefficient between sample sociological characteristics and behavior attitude (Table 4). Age 
was associated with perceived severity and perceived behavioral disorders $(p<0.05)$. Perceived threat, Perceived benefits, Perceived barriers, Self-efficacy, Cues to actionare associated with a number of social characteristics of residents $(\mathrm{p}<0.01)$, See Table 4, Table 5 and Table 6 for details.

Table 4. Spearman correlation coefficient of sample sociological characteristics and behavior attitude.

\begin{tabular}{|c|c|c|c|}
\hline sociological characteristics variable & Behavior attitude variable & $\mathbf{r}_{\mathrm{s}}$ & $P$ \\
\hline \multirow[t]{3}{*}{ Age } & Perceived severity & 0.068 & 0.04 \\
\hline & Perceived barriers & 0.238 & 0.00 \\
\hline & Cues to action & -0.202 & 0.00 \\
\hline \multirow[t]{11}{*}{ Education } & A1 & -0.199 & 0.00 \\
\hline & A2 & -0.213 & 0.00 \\
\hline & $\mathrm{A} 3$ & -0.241 & 0.00 \\
\hline & B2 & -0.137 & 0.00 \\
\hline & $\mathrm{C} 1$ & -0.202 & 0.00 \\
\hline & $\mathrm{C} 3$ & -0.208 & 0.00 \\
\hline & C6 & -0.108 & 0.00 \\
\hline & E3 & -0.148 & 0.00 \\
\hline & E4 & -0.124 & 0.00 \\
\hline & E5 & -0.116 & 0.00 \\
\hline & F2 & 0.118 & 0.00 \\
\hline \multirow[t]{7}{*}{ Profession } & A1 & 0.290 & 0.00 \\
\hline & A2 & 0.252 & 0.00 \\
\hline & $\mathrm{A} 3$ & 0.257 & 0.00 \\
\hline & B2 & 0.152 & 0.00 \\
\hline & B4 & 0.163 & 0.00 \\
\hline & D1 & 0.113 & 0.00 \\
\hline & D4 & 0.109 & 0.00 \\
\hline \multirow[t]{13}{*}{ Income (per month) } & A1 & -0.275 & 0.00 \\
\hline & $\mathrm{A} 2$ & -0.293 & 0.00 \\
\hline & $\mathrm{A} 3$ & -0.281 & 0.00 \\
\hline & B2 & -0.120 & 0.00 \\
\hline & B4 & -0.179 & 0.00 \\
\hline & $\mathrm{C} 1$ & -0.132 & 0.00 \\
\hline & $\mathrm{C} 3$ & -0.163 & 0.00 \\
\hline & $\mathrm{C} 4$ & -0.188 & 0.00 \\
\hline & $\mathrm{C} 6$ & -0.144 & 0.00 \\
\hline & E2 & -0.123 & 0.00 \\
\hline & E3 & -0.237 & 0.00 \\
\hline & F1 & -0.202 & 0.00 \\
\hline & D5 & 0.135 & 0.00 \\
\hline
\end{tabular}

Table 5. One way ANOVA of sample sociological characteristics and behavior attitude.

\begin{tabular}{llll}
\hline Sociological characteristics variable & Behavior attitude classification variable & F & P \\
\hline Education & Perceived susceptibility & 13.029 & 0.00 \\
Profession & Perceived barriers & 4.020 & 0.00 \\
& Cues to action & 2.671 & 0.00 \\
Income (per month) & Perceived severity & 3.335 & 0.00 \\
& Perceived benefits & 5.071 & 0.00 \\
& Perceived barriers & 3.435 & 0.00 \\
& Cues to action & 4.956 & 0.00 \\
\hline
\end{tabular}

Table 6. Independent-Samples $t$ Test of sample sociological characteristics and behavior attitude.

\begin{tabular}{llll}
\hline Sociological characteristics variable & Behavior attitude classification variable & t & P \\
\hline Gender & Perceived susceptibility & 2.783 & 0.01 \\
& Perceived severity & 2.747 & 0.01 \\
Working condition & Perceived benefits & -3.435 & 0.00 \\
\hline
\end{tabular}




\section{Discussion}

This study found that age, education, occupation, monthly income and work location were closely related to multiple epidemic prevention and control behaviors. It is well known that the current COVID 19, although there is no specific drug or vaccine, People's understanding of coronavirus is also very limited, but many healthy behaviors conducive to epidemic prevention and control have been summarized through practice in this outbreak, such as wearing masks, washing hands frequently, avoiding public gatherings, minimizing going out, and avoiding social activities. This study explores the relationship between residents' basic sociological characteristics and these epidemic prevention behaviors, hoping to provide reference for more countries and regions.

\subsection{Focus on the Availability and Effectiveness of Older Adults in Accessing Vectors for Epidemic Information}

Age has a negative correlation in perceived barriers, indicating that the older the person is, the greater the perceived barriers to beneficial behaviors are. Considering that age is also positively correlated in cue to action, it indicates that cue to action may be the key reason why the elderly cannot better control their behaviors. As far as China is concerned, most of the elderly over 60 years old have a low level of education, mainly junior high school and primary school education. With the increase of age, the cognitive ability of these elderly people is further declining. The vast majority of the elderly (especially those over 70 years old) will not use smart phones. For this epidemic disease, the information of the epidemic situation released by relevant departments of the state is spread through the Internet, smart phones and other channels in addition to television and other news media, The frequency and speed of network information transmission is much higher than that of traditional mass media, which causes a certain lag in the acquisition of information by the elderly, Therefore, due to the lack of timely access to information, the elderly have insufficient awareness of the protection against the epidemic, and the corresponding protection materials (such as masks, hand sanitizers, etc.) cannot be timely obtained. Inadequate information, inadequate supplies, and the prior habits of most older people make it difficult to adapt to the critical behavior of "home isolation" required by the epidemic, Older people are more likely to go out in public blindly. Therefore, relevant departments should pay close attention to the elderly, especially the elderly who live alone, and give priority to ensuring the popularization of materials and information for these people.

\subsection{Pay Attention to the Attitude and behavIor of Disease Prevention Measures of the Group with Low Educational Background}

The higher the level of education, the greater the awareness of the seriousness of the epidemic and the greater the compliance with official requirements for epidemic prevention. Among them, the three items of perceived severity were strongly correlated with educational background, occupation and monthly income, This suggests that people are more likely to adopt healthy behaviors when they are aware that someone around them has been diagnosed, that they may be infected by the virus when they travel, and that they live in an area with a severe epidemic. China has published a map of the outbreak on several media platforms, which is updated daily, and even a mobile APP can be used to check whether there are confirmed or suspected cases in the region where you live. Many residents in China have used this information technology to better understand the distance between the outbreak and themselves, which has stimulated their ability to protect themselves and made them more willing to adopt healthy behaviors. On the contrary, people with low educational background do not pay enough attention to the epidemic situation and carry out insufficient epidemic prevention and control measures, which will lead to negligence of prevention and control measures and increase the probability of infection.

\subsection{Monthly Income Is an Important Factor in Adopting Healthy Behaviors}

There was a negative correlation between monthly income and multiple behaviors. The higher the income, the higher the likelihood of adopting healthy behaviors, and the higher the awareness of preventing and controlling the epidemic. Generally speaking, monthly income is positively correlated with education level in China, so people with high monthly income are also people with high education level. In the survey, people with higher education and incomes were more likely to stay at home and quarantine, washing their hands and wearing masks until the outbreak was over. They also pay more attention to information from official national channels. According to $\mathrm{p} . \mathrm{j}$. tichenor's knowledge-gap hypothesis, these people acquire information faster and more widely than others, Their educational background also helps them better understand the disease and what needs to be done to prevent and control the epidemic, which leads to higher behavioral compliance. In contrast, people with lower monthly incomes tend to have lower education levels, less access to knowledge and information, and are more likely to go out for a living, At the same time, due to the economic level, the possibility of not being able to obtain effective epidemic prevention materials (such as masks, hand sanitizers, etc.) is also greater, resulting in loopholes in epidemic prevention and control. Therefore, in the case of shortage of epidemic prevention manpower resources, the focus will be more epidemic prevention manpower distribution in low-income, low educational population population. The community residents with high education and high income can serve as the secondary key area.

\subsection{Give Play to the Social Function of All Walks of Life to Ensure the Supply of Life Materials}

Occupation and the need to work outside the home are also important factors. Home quarantine and less travel are key actions in the prevention and control of this outbreak, but it 
will take the full cooperation of many industries to achieve this goal. China has an advanced logistics and express delivery industry. When isolated at home, people rely on delivery men, door-to-door delivery services in supermarkets, and logistics and express delivery to ensure the life of thousands of households. These delivery men and delivery men have become a highly concerned occupation in the work of this epidemic. China has implemented a contactless delivery service in the logistics and express delivery industries. When delivering goods, couriers or takeaways will place the goods in a designated place in the community or building, and the recipients will go to the designated place to pick up the goods, so as to ensure that there is no direct contact between people to the greatest extent. The survey found that the biggest barrier to occupational and health behavior was the difficulty in obtaining supplies such as face masks and hand sanitizers. In the case of shortage of materials, priority should be given to the distribution of materials to prevent the epidemic, to ensure the basic operation of the city, to ensure the supply of materials for medical personnel, to ensure that they escort for life in their own safety. At the same time, the operation status of the post that supplies the necessary materials for home quarantine should be considered during the epidemic period.

\subsection{Positive Self-efficacy Can Encourage People to Adhere to Healthy Behaviors, so as to Ensure Their Health Without Being Infected}

In this cross-sectional survey conducted in China, the majority of residents believe that the prevention and control measures are effective and can be carried out to the end of the epidemic. Self-efficacy depends on many factors and is an important factor in healthy behavior, In this epidemic disease, timely and effective access to information and high frequency of multi-channel dissemination of prevention information can enhance the public's confidence in disease prevention and control, so as to improve self-efficacy and adhere to the adoption of healthy behavior. In the early stage of the epidemic in China, the mainstream media quickly gathered, set up front-line reporting positions [15], and timely released accurate information on the epidemic. The authoritative release of the mainstream media injected a shot of "tonic" to the whole nation-A survey on covid-19 epidemic showed that in late January 2020, people's confidence in government governance, medical treatment, scientific research and other aspects was significantly enhanced [16]. The media plays an important role in timely responding to social concerns and stabilizing the people's minds. The vast majority of residents $(42.7 \%)$ paid close attention to the epidemic information during the epidemic period. Meanwhile, the vast majority of residents (49.8\%) believed that the information released by the news media or online official media was very useful and could obtain sufficient information for prevention and control in a timely manner. The openness and transparency of information dissemination in mainstream media also provide good reference value for the world to do a good job in the prevention and control of COVID-19 epidemic.

\section{Conclusion}

In 2020, the world is facing the ravages of virus. According to the characteristics of epidemic spread, the world health organization and various countries have introduced various protection measures. Everyone is a soldier in this battle. Only by working together can the virus be defeated. In terms of the implementation of epidemic prevention measures, the government or social organizations should pay more attention to the characteristics of the key population and carry out targeted measures, especially the elderly, the elderly living alone, the low-income people with low educational background. At the same time, we will focus on the compliance of prevention and control measures for low-income and low-educated people, and intensify publicity and material support. The government should give full play to the social function of all walks of life, ensure the supply of materials for people who are quarantined at home, intensify the media propaganda, and release the epidemic information in an open, transparent, accurate and timely manner, so as to increase the information of residents against the virus.

\section{References}

[1] Sun P, Lu X, Xu C, Sun W, Pan B. Understanding of COVID-19 based on current evidence. J Med Virol. 2020 Jun; 92 (6): 548-551. doi: 10.1002/jmv.25722. Epub 2020 Mar 5. PMID: 32096567; PMCID: PMC7228250.

[2] National health commission, PRC. Covid-19 protocol for diagnosis and treatment (seventh edition). [EB/OL]. (2020-03-09).

http://www.nhc.gov.cn/yzygj/s7652m/202003/a31191442e294 74b98bfed5579d5af95.shtml

[3] Yuan JM, Ren H, Sun Y, Wang Ke Chen MW.. Analysis and reflection on the transmission routes of SARS-COV-2.[J/OL]. Journal of Xi'an Jiaotong University (Medical Sciences) http://kns.cnki.net/kcms/detail/61.1399.R.20200317.0906.002. html

[4] Bai Y, Yao L, Wei T, Tian F, Jin DY, Chen L, Wang M. resumed Asymptomatic Carrier Transmission of COVID-19. JAMA. 2020 Feb 21. doi: 10.1001/jama.2020.2565. [Epub ahead of print].

[5] Qiu J. Covert coronavirus infections could be seeding new outbreaks. Nature. 2020 Mar 20. doi: 10.1038/d41586-020-00822-x. [Epub ahead of print].

[6] Wang C, Hornby PW, Hayden FG, Gao GF. A novel coronavirus outbreak of global health concern. Lancet [published online January 24, 2020]. DOI: 10.1016/S0140-6736(20)30185-9. Paules CI, Marston HD, FauciAS. Coronavirus infection-more than just the common cold. JAMA [published online January 23, 2020]. DOI: 10.1001/jama.2020.0757

[7] S. Zhao, Q. Lin, J. Ran, S. S. Musa, G. Yang, W. Wang, et al. Preliminary estimation of the basic reproduction number of novel coronavirus (2019-nCoV) in China, from 2019 to 2020: a data-driven analysis in the early phase of the outbreak Int $\mathrm{J}$ Infect Dis, 92 (2020), pp. 214-217, 10.1016/j.ijid.2020.01.050. 
[8] C. Biscayart, P. Angeleri, S. Lloveras, T. Chaves, P. Schlagenhauf, A. J. Rodriguez-MoralesThe next big threat to global health? 2019 novel coronavirus (2019-nCoV): What advice can we give to travellers? - Interim recommendations January 2020, from the Latin-American Society for Travel Medicine (SLAMVI) Travel Med Infect Dis (2020), Article 101567, 10.1016/j.tmaid.2020.101567.

[9] W. G. Carlos, C. S. Dela Cruz, B. Cao, S. Pasnick, S. JamilNovel Wuhan (2019-nCoV) coronavirus Am J Respir Crit Care Med, 201 (2020), pp. P7-P8, 10.1164/rccm.2014P7.

[10] World Health Organization, WHO Director-General's opening remarks at the media briefing on COVID-19 - 23 March 2020. https://www.who.int/dg/speeches/detail/who-director-generals-opening-remarks-at-the-media-briefing-on-covid-19---23-m arch-2020.

[11] World Heaith Organization, Coronavirus disease (COVID-19) advice for the public, https://www.who.int/emergencies/diseases/novel-coronavirus2019/advice-for-public
[12] Zhonghua Liu Xing Bing Xue Za Zhi. The epidemiological characteristics of an outbreak of 2019 novel coronavirus diseases (COVID-19) in China 2020 Feb 17; 41 (2): 145-151. doi: 10.3760/cma.j.issn.0254-6450.2020.02.003. [Epub ahead of print].

[13] World Heaith Organization, WHO Director-General's opening remarks at the media briefing on COVID-19 - 5 March 2020, https://www.who.int/dg/speeches/detail/who-director-generals-opening-remarks-at-the-media-briefing-on-covid-19---5-mar ch-2020

[14] Champion VL, Scott CR: Reliability and validity of breast cancerscreening belief scales in African American women. Nurs Res. 1997, 46 (6): 331-337.

[15] Gao XY, Zhao XQ. Responsibility and mission of mainstream communication in public health emergencies [J]. Chinese Editors Journal, 2020 (Z1): 4-9.

[16] Wang JX. Information, trust, confidence: The core influencing factors of social mentality under epidemic prevention and control [N]. Guangming Daily, 2020- 02-07. 